\section{Anaesthesia for radiotherapy}

To the Editor:

We note with interest Dr Maltby's article' on sixteen repeat ketamine anaesthetics to a child, for radiotherapy in the prone position. Our department* has given 176 anaesthetics in the last year to twelve children (aged three to five) to enable radiotherapy to be carried out either in the prone or the supine position, due to the inability of the children to co-operate adequately whether sedated or not.

The first two-thirds of these utilised either IM or IV ketamine with atropine and without any premedication. The children had anaesthetics five times a week for up to seven weeks, and the experience for child, parent, nursing staff and anaesthetist can only be said to have been harrowing. Apart from lack of amnesia and the distress of frequent injections, other problems we have encountered with ketamine have included gencralised crythema, excess salivation, marked laryngospasm, dysphoria, unpleasant hallucinations, rapid exhaustion of veins, sore muscles, prolonged vomiting and inability to return to early feeding. Prolonged recovery also had a disadvantage in tying a busy anaesthetist to the radiotherapy department until the children were safely awake.

The last one-third of these patients have been given an oral temazepam pre-medication (0.6-0.8 $\mathrm{mg} \cdot \mathrm{Kg}^{-1}$ ) with or without atropine according to the child one hour prior to treatment, and then induced and maintained with an inhalational technique alone, using enflurane/nitrous oxide/oxygen. During treatment anaesthesia is maintained by insufflating the gaseous mixture into a normal plastic Guedel-type oral airway by means of plastic tubing and a small metal connector heat sunk into the airway. By this means the depth of anaesthesia can be easily maintained (or indeed increased) and we avoid any injections. It is arguable whether scavenging of gases in such a circumstance is necessary and we have not pursued this.

The children, once their and their parents confidence is won, readily accept the technique and

*Department of Anaesthesia, Addenbrooke's Hos pital, Cambridge. indeed place their faces into the anaesthetic mask without any crying or struggling. There have been fewer problems with salivation and laryngospasm, no dysphoria beyond the twenty-minute recovery period, their veins are preserved and they have no residual soreness, they return to feeding almost instantly without vomiting, and the rest of their day and night is unmarred by residual drug or emotional effects. The anaesthetist is also released early due to the quick recovery period. We do not consider enflurane induced hepatitis to be a problem in this circumstance and accordingly now routinely use this enflurane technique.

Dr Howard S. Smith FFarCS

Department of Anaesthesia

Hinchingbrooke Hospital

Huntingdon

Cambridgeshire

England

\section{REFERENCE}

1 Maltby JR, Warkins DMB. Repeat kelamine anaesthesia of a child for radiotherapy in this prone position. Can Andesth Soc J 1983; 30: 52(i-30.

\section{Packaging of single dose vials of local anaesthetics}

To the Editor:

Injectable local anaesthetics are supplied in either "multi-dose" or "single-dose" formats. "Multidose" bottles usually contain, in addition to the medication, agents (methylparabens) to retard bacterial growth, and to prolong shelf-life, should a needle-entry result in bacteriological contamina tion, and also a preservative or stabilizer (metabisulphites) to prevent decomposition or loss of potency of epinephrine. "Singe-dose" bottles are intended to be discarded after their first use; if they do not contain epinephrine, neither of the above additives will be included. In fact, methylparabens are contra-indicated if the local anaesthetic is to be given by the intravenous, epidural or subarachnoid 
route. As a result, in addition to labelling, there should be a mechanism in the packaging, to alert the practitioner when a "single-dose" bottle has been previously entered. A recent incident made me aware that the presence of such a mechanism cannot be taken for granted.

The intention was to withdraw all $20 \mathrm{cc}$ of bupivacaine $\mathrm{HCl}$ (Marcaine) 0.5 per cent (without epinephrine) from a "single-dose" bottle, but only $10 \mathrm{cc}$ were recovered. Close inspection revealed no evidence of previous use: the sealing ring was intact, the "bend-back" tab was still present and could be bent down or back to reveal the rubber stopper, and no needle marks were discernible in the stopper.

Several questions immediately came to mind. (1) Were the missing $10 \mathrm{cc}$ omitted during the packaging proccss? (2) Did they cvaporate or leak out of a damaged seal or cracked bottle? (3) Were they removed by someone else? (4) Were all the original $20 \mathrm{cc}$ removed, and $10 \mathrm{cc}$ of something else inserted? (5) If previous entry had been made, why was there no evidence of this? Obviously, this method of sealing "single-dose" bottles was inadequate and potentially dangerous

Communication with the Health Protection Branch of Health and Welfare Canada ${ }^{1,2}$ revealed that there are no regulations governing the manner in which injectable medication is sealed, nor to differentiate between "single-dose" and "multi-dose" containers. In addition, although regulations have recently been drafted concerning security packaging, these apply only to non-prescription diugs. ${ }^{3}$

However, Winthrop Laboratories (the manufacturer) after my personally communicating with them, did recognize that the seal was deficient and the following remedial action has been taken. Formerly, for "single-dose" bottles of Marcaine and Carbocaine, there was a metal disc under the sealing ring, and over the stopper. This disc had a central hole to allow a needle to reach and pierce the stopper, without removing the sealing ring, but simply by bending back the tab. In the future, I have been advised by the company, the metal disc will not have a hole. Thus to reach the contents, the sealing ring will have to be broken and removed, and then the disc removed. This ensures that subsequent users will recognize that the bottle was previously entered.

This method of sealing is not unique - it is used by other companies to differentiate between "singledose" non-preserved medication and "multi-dose" preserved medication. Why Winthrop Laboratories would seal a "single-dose" bottle in a manner that would allow it to be mistaken for and used as a "multi-dose" bottle, and why the Health Protecrion Branch has no regulation to prevent them from marketing their products in this way, are two questions which must be answered so that this potentially dangerous situation does not repeat itself.

I have one final comment regarding "multi-dose" injectables. How does a subsequent user know that the contents of a previously opened "multi-dose" bottle are the remainder of what the manufacturer originally put into the vial? Could someone not remove all the contents and insert something else? In the light of the "Tylenol Incident" in the U.S.A., I believe it would be prudent to eliminate completcly the use of "multi-dose" containers, at least in areas where they will be used by more than one practitioner, or are available to a multitude of people working at various levels of the health care system.

\section{R.M. Gardner MD FRCP(c)}

Specialist in Anaesthesia

20-170 Sherway Drive

Etobicoke, Ontario

REFERENCES

1 Food and Drug Regulations, Health \& Welfare Canada.

2 Personal communication - Mr. Sarfraz Ahmad, Health Protection Branch, Health \& Welfare

Canada, Scarborough, Ont.

3 Information Letter No. 648, April 29, 1983, Health Protection Branch, Health and Welfare Canada.

\section{Anévrisme après canulation de l'artère radiale}

Au rédacteur:

L'anévrisme après canulation de l'artère radiale est une complication tardive mais peu fréquente malgré la généralisation du cathétérisme de cette artère en 